\title{
PAULO FREIRE NOS PROJETOS PEDAGÓGICOS DOS CURSOS DE LICENCIATURA EM CIÊNCIAS AGRÍCOLAS DAS INSTITUIÇÕES FEDERAIS DE ENSINO NO BRASIL
}

\author{
Apresentação: Comunicação Oral \\ Cirdes Nunes Moreira ${ }^{1}$; Monica Lopes Folena Araújo ${ }^{2}$
}

\begin{abstract}
Resumo
Foram analisados os Projetos Pedagógicos dos Cursos de Licenciatura em Ciências Agrícolas da Universidade Federal Rural de Pernambuco - UFRPE; do Instituto Federal de Educação, Ciência e Tecnologia Catarinense - IFCatarinense e do Instituto Federal de Educação, Ciência e Tecnologia do Rio Grande do Sul - IFRS. O presente estudo teve por objetivo identificar como o referencial freireano é utilizado na concepção desses cursos, oferecidos no âmbito de instituições federais de ensino no país. Autonomia, consciência, criatividade, criticidade, diálogo, emancipação, esperança e humanização, elencadas por Paulo Freire, são contribuições importantes para a construção de uma educação libertadora, problematizadora e transformadora, fundamentais ao processo de formação dos professores das Ciências Agrícolas, Agrárias e da Educação do Campo. No presente trabalho, de cunho qualitativo, o procedimento de busca consistiu em localizar as citações das obras de Freire, em cada um dos PPC analisados, identificando que referências aparecem e em quais contextos dos referidos documentos. O estudo revelou a pequena presença da contribuição de Freire, predominantemente circunscrita ao ementário dos componentes curriculares, com apenas cinco títulos do autor citados ao longo dos três documentos analisados. A despeito disto, o aporte freireano pode estar inserido no contexto da oferta das disciplinas do curso, notadamente naquelas vinculadas às ciências humanas, admitindo-se que o Projeto Pedagógico pode não traduzir de forma completa a realidade daquilo que se aborda na sala de aula. O enfrentamento das questões de natureza sócio-política-ambiental contemporâneas, onde as instituições de educação exercem importante papel na formação de cidadãos críticoreflexivos, assume, no caso mais específico da formação profissional direcionada aos trabalhos que envolvem as problemáticas do meio rural, o desafio de (re)pensar seus projetos de educação, trazendo para eles a perspectiva transformadora, sintonizada às necessidades da maioria da população. Neste sentido, as contribuições de Freire, muito para além das obras "Extensão ou Comunicação?" e "Pedagogia da autonomia", precisam estar mais presentes, norteando de maneira bastante efetiva os processos de construção participativa dos novos rumos para a formação dos licenciados em Ciências Agrícolas.
\end{abstract}

Palavras-Chave: Paulo Freire, Licenciatura em Ciências Agrícolas, Projeto Pedagógico de Curso.

\footnotetext{
1 Engenheiro Agrônomo do Departamento de Educação da Universidade Federal Rural de Pernambuco (DEd/UFRPE). Mestre em Extensão Rural e Desenvolvimento Local. Pesquisador no Grupo de Pesquisa em Formação e Prática Pedagógica de Professores de Ciências e Biologia (FORBIO/UFRPE). Doutorando do Programa de Pós-graduação em Ensino das Ciências (PPGEC/UFRPE). E-mail: cirdesnm @ gmail.com 2 Professora Orientadora, Departamento de Educação (DEd/UFRPE), Programa de Pós-graduação em Ensino das Ciências (PPGEC/UFRPE), Doutora em Educação, Pesquisadora da Cátedra Paulo Freire da Universidade Federal de Pernambuco (UFPE), Líder do Grupo de Pesquisa em Formação e Prática Pedagógica de Professores de Ciências e Biologia (FORBIO/UFRPE). E-mail: monica.folena@gmail.com
} 


\section{Introdução}

O Curso de Licenciatura em Ciências Agrícolas, segundo dados disponíveis em nove (9) de outubro de 2016, na página virtual do Ministério da Educação e Cultura - MEC (http://emec.mec.gov.br/emec/nova), é oferecido em cinco instituições federais de ensino no país: a Universidade Federal Rural de Pernambuco - UFRPE; o Instituto Federal de Educação, Ciência e Tecnologia Catarinense - IFCatarinense; o Instituto Federal de Educação, Ciência e Tecnologia do Rio Grande do Sul - IFRS; a Universidade Federal Rural do Rio de Janeiro - UFRRJ e o Instituto Federal do Mato Grosso - IFMT. O portal apresenta ainda, além das cinco Licenciaturas em Ciências Agrícolas mencionadas, a oferta no país de dezesseis (16) Licenciaturas em Ciências Agrárias e 57 (cinquenta e sete) Licenciaturas em Educação do Campo, estas últimas parecendo serem uma tendência recente, com a abertura de tantas ofertas nas instituições do país, nos últimos dez anos.

Das cinco instituições que oferecem o Curso de Licenciatura em Ciências Agrícolas, Santos e Benevides (2015) anunciaram a extinção do curso que vinha sendo oferecido desde 2011, pelo IFMT; e a UFRRJ, também em 2015, ao aprovar o Projeto Pedagógico do Curso de Licenciatura em Educação do Campo, admitiu que o Curso de Licenciatura em Ciências Agrícolas, pioneiro entre os cursos no país, oferecido desde o ano de 1963 pela instituição, já não "dá conta das especificidades socioculturais e educacionais que se reconhecem como diversificadas e politicamente enraizadas nas lutas democráticas pela alteridade" (UFRRJ, 2010, p. 5). Assim, restam funcionando no país os Cursos de Licenciatura em Ciências Agrícolas oferecidos pela UFRPE, desde 1970; pelo IFCatarinense e pelo IFRS, estes dois últimos, desde o ano de 2010, o que delimita o universo do presente estudo, ou seja, os cursos oferecidos pela UFRPE, pelo IFCatarinense e pelo IFRS.

Dentre os três cursos analisados, o mais antigo é o de Licenciatura em Ciências Agrícolas oferecido pela Universidade Federal Rural de Pernambuco - UFRPE, criado pela Resolução 12/70 do Conselho de Ensino e Pesquisa da UFRPE e autorizado pelo Parecer 320/72 do Conselho Federal de Educação. Entre os anos de 1972 a 1983, a instituição chegou a habilitar quase duzentos professores agrícolas em exercício nas escolas agrotécnicas de todas as regiões do país. Entre 1984 até 2002 foram formados 435 licenciados (UFRPE, 2004). O curso é presencial, tem duração de 2.835 horas, é ministrado em Recife - PE e oferece oitenta (80) vagas anuais.

O curso oferecido pelo Instituto Federal de Educação, Ciência e Tecnologia Catarinense - IFCatarinense é presencial e iniciou suas atividades em $1^{\circ}$ de março de 2010 , 
oferecendo anualmente quarenta vagas, em 2.800 horas de duração, no Campus de Araquari, localizado no município de mesmo nome, distante $182 \mathrm{~km}$ da capital catarinense (IFCatarinense, 2013). Também o curso oferecido pelo Instituto Federal de Educação, Ciência e Tecnologia do Rio Grande do Sul - IFRS, é presencial, iniciou suas atividades na mesma data do curso oferecido pelo IFCatarinense, tem uma duração um pouco maior (3.000 horas) e oferece anualmente trinta vagas, na cidade de Sertão, distante $330 \mathrm{~km}$ de Porto Alegre (IFRS, 2013).

Refletindo a respeito das concepções de Paulo Freire, no âmbito da educação, a autonomia, a consciência, a criatividade, a criticidade, a perspectiva dialógica, a emancipação, a esperança e a humanização, são contribuições importantes para a construção de uma educação libertadora, problematizadora e transformadora, fundamentais que são ao processo de formação dos professores das Ciências Agrícolas, Agrárias e da Educação do Campo, como para outras profissões.

Acontece que, por outro lado, com as reformas do ensino em 1968 (Lei 5540) e em 1971 (Lei 5692), Oliveira apud Feitosa (2006) chama atenção que a institucionalização dos primeiros Cursos de Licenciatura em Ciências Agrícolas, na década de 70, esteve articulada ao processo expansão e revitalização do ensino técnico agrícola e de profissionalização do magistério em todos os níveis e ramos do ensino, pelos Cursos de Licenciatura. Naquele contexto, os cursos de Licenciatura em Ciências Agrícolas, notadamente o da UFRRJ, que foi o primeiro a ser oferecido no país, balizavam seu processo formativo pelo modelo pedagógico do Sistema Escola-Fazenda, cuja concepção de educação técnica firmava-se na relação produtivista e unidirecional do mercado, onde a produção agropecuária assumia forte identidade empresarial.

Diante do exposto, considerando as contribuições de Freire e as reflexões em torno da educação voltada às expectativas da sociedade e sua perspectiva transformadora, enfaticamente pautadas nos últimos anos, o presente trabalho tem como problema de pesquisa: Como o referencial teórico de Paulo Freire está presente atualmente nos PPC dos cursos de Licenciatura em Ciências Agrícolas? Assim, temos por objetivo analisar como o referencial teórico de Paulo Freire é utilizado na concepção dos PPC dos cursos de Licenciatura em Ciências Agrícolas no Brasil, tendo como universo de pesquisa as três instituições federais de ensino que ministram atualmente o referido curso, quais sejam: a Universidade Federal Rural de Pernambuco - UFRPE; o Instituto Federal de Educação, Ciência e Tecnologia Catarinense - IFCatarinense; e o Instituto Federal de Educação, Ciência e Tecnologia do Rio Grande do Sul - IFRS. 


\section{Fundamentação Teórica}

Em relação aos objetivos dos cursos de formação de licenciados em Ciências Agrícolas/Agrárias, Moraes (2014) destaca a necessidade do atendimento das demandas existentes por profissionais licenciados para lecionarem disciplinas na área das Ciências Agrárias, nas redes de educação básica e profissionalizante, pública e privada, além dos organismos sociais que desenvolvem educação não escolar. Tais instituições requerem:

\footnotetext{
Educadores com sólida formação pedagógico-científica e tecnológica, com conhecimento da dinâmica da realidade e da educação agrícola, dos sistemas de ensino e da escola enquanto realidades concretas de um contexto histórico-social. Capazes de buscar alternativas frente às diferentes situações da prática educativa em suas diversas modalidades, que consigam investigar e produzir conhecimentos sobre o meio ambiente e as finalidades da educação agrícola, bem como sobre os meios apropriados de formação humana;

Licenciados que desenvolvam atividades didático-pedagógicas que proporcionem a construção de conhecimentos multi e interdisciplinar do currículo, com ações teórico-práticas compatíveis com a realidade vivenciada e suas potencialidades de mudança e com ênfase na: proteção, preservação, conservação e recuperação do ambiente (MORAES, 2014, p. 648-649).
}

O estudo do Projeto Pedagógico de Curso - PPC pode oferecer revelações a respeito de um curso e da instituição ofertante, pois nele estão definidas as ações educativas para que os cursos cumpram seus propósitos e intencionalidades. Assim, para Gadotti, apud Souza (2006, p.39), tal projeto “deve ter uma direção política, ele é sempre inconcluso, é uma etapa em direção a uma finalidade que permanece como horizonte da escola”. Aqui cabe ressaltar, conforme Veiga (2006), se tratarem de processos permanentes de reflexão e discussão dos problemas da instituição formadora, na busca de alternativas viáveis à efetivação de sua intencionalidade, sem perder de vista os interesses e forças que neles gravitam e que findam por delimitar pedagogicamente as ações educativas.

Moreira e Araújo (2016), analisando projetos pedagógicos do Curso de Agronomia de três universidades federais rurais do Norte e Nordeste do Brasil, identificaram situações distintas no tocante à abordagem de Educação Ambiental, neles presente:

Uma delas com indícios de uma Educação Ambiental conservadora, desvinculada da natureza social, cultural e política; outra privilegiando um viés mais regionalista, com ênfase no desenvolvimento econômico e presença de alguns matizes de sustentabilidade, associados à busca da cidadania e justiça; e noutra, uma abordagem de Educação Ambiental integral, contextualizada do ponto de vista da complexidade que envolve as questões da sustentabilidade, inclusive da sua natureza social, cultural e política (p. 1).

A contribuição de Paulo Freire para a concepção dos cursos, por outro lado, tem sido objeto de interesse de diversos autores. Na Agronomia, por exemplo, Callou et al. (2008), ao analisar o estado da arte do ensino de Extensão Rural no Brasil, contando com a contribuição 
de mais de sessenta professores dos cursos de graduação e pós-graduação das universidades do país, identificou que, no âmbito da literatura sugerida no componente curricular "Extensão Rural”, Freire é o autor que encabeça a lista dos mais citados, particularmente com o título "Extensão ou Comunicação?".

Os PPC analisados no presente estudo, devem refletir realidades diferenciadas, quer do ponto de vista temporal, pois uma das instituições foi criada no início do século passado, enquanto as outras duas foram criadas bem recentemente, ambas no ano de 2008; regional, vez que uma instituição está localizada na Região Nordeste e duas na Região Sul; além da própria natureza institucional, visto se tratarem de uma universidade e dois institutos.

Assim, a proposta pedagógica de Freire, tendo como alicerce a reflexão e o diálogo, termina por se configurar numa perspectiva de transformação dos sujeitos e da própria sociedade, dada sua força de mudança e de libertação, conforme destacam Mariani e Carvalho (2009).

Evidentemente cumpre aqui ressalvar que a análise do PPC, tão somente, não é suficiente para a compreensão da realidade do processo de ensino-aprendizagem. Vidal (2010) aponta quatro elementos que constituem a docência: a "trajetória escolar dos professores", a "relação intersubjetiva estabelecida com diferentes atores sociais", a "a confrontação dos sujeitos com as condições materiais da existência e do trabalho docente" e "a prática docente como tradição inventada, efeito de uma memorização do passado". Tais elementos resgatam ideias importantes, que têm a ver como a própria história de vida dos docentes, que antes de se tornarem professores, são sujeitos que se constituíram como alunos; com suas perspectivas relacionais, dentro e fora da escola, na convivência com outros sujeitos, envolvidos ou não com a escola, aí presentes outras dimensões, tais como gênero, etnia, classe e geração, que resultam na "interpenetração entre a vida profissional e vida pessoal” (VIDAL, 2010, p. 718-719). A "materialidade da escola" que se traduz nos objetos, espaço, tempo escolar, carreira e urgências da classe, com os quais o professor lida diariamente, e os processos de construção de identidades docentes, a partir das experiências, complementam características que são importantes para o entendimento dos sentidos e significados da docência.

Passaremos a apresentar o percurso metodológico que norteou o presente estudo.

\section{Metodologia}


O presente trabalho, de cunho qualitativo, consistiu em uma análise documental. Para Oliveira (2007, p. 69), a pesquisa documental “[...] caracteriza-se pela busca de informações em documentos que não receberam nenhum tratamento científico, como relatórios, revistas, cartas, filmes [...]”. Nesse sentido, compreendemos que os projetos pedagógicos de curso PPC analisados são documentos desta natureza.

Foram analisados três projetos pedagógicos, todos eles de instituições federais de ensino, sendo dois deles de institutos federais de ensino da Região Sul do Brasil (IFCatarinense, 2013; IFRS, 2013) e outro de uma universidade nordestina (UFRPE, 2004). Do ponto de vista cronológico, os projetos analisados foram publicados entre os anos de 2004 e 2013, ou seja, correspondem a um período relativamente recente.

O procedimento de busca consistiu em localizar as citações das obras de Freire, em cada um dos PPC analisados, identificando que referências aparecem, se estão no contexto da concepção central do projeto, ou vinculadas especificamente aos ementários dos componentes curriculares, identificando, nestes casos, em quais deles são encontrados os referidos registros.

Daremos prosseguimento com a apresentação e discussão dos resultados alcançados.

\section{Resultados e Discussão}

Os três projetos pedagógicos analisados apresentam referências de Paulo Freire na sua concepção. No conjunto dos documentos analisados, as referências da contribuição de Freire aparecem apenas treze vezes, o que representa um quantitativo muito pequeno, sobretudo se considerarmos que os três documentos totalizam 262 (duzentas e sessenta e duas páginas), além é claro, dada a natureza das temáticas ali presentes, onde as contribuições de Freire poderiam estar incorporadas de forma mais evidente.

O título "Extensão ou Comunição?” (FREIRE, 2014), nas edições de 1983, 1985, 1988 e 2011, é citado nos três documentos e é a obra que aparece com maior frequência, cinco vezes ao todo. No PPC do IFCatarinense (2013), Freire (2014) é citado duas vezes, sempre em ementários de componentes curriculares, quais sejam: Estágio Supervisionado I (p. 47) e Extensão Rural (p. 65). Já no PPC do IFRS (2013), “Extensão ou Comunicação?” é citado uma única vez, na ementa do componente Extensão Rural (p. 86). No PPC de Licenciatura em Ciências Agrícolas da UFRPE, o título é citado duas vezes, na ementa do componente curricular Metodologia do Ensino Agrícola, e na bibliografia geral do documento.

Aqui é importante destacar que esses achados em relação ao título "Extensão ou Comunicação?" coincidem com o estudo realizado por Callou et al. (2008) que revelou ser 
este o título mais citado de Freire, entre as literaturas sugeridas no ensino da Extensão Rural nos cursos de graduação e pós-graduação no Brasil.

O outro título da obra de Freire que se destacou no levantamento realizado nos PPC analisados, foi "Pedagogia da autonomia: saberes necessários à prática educativa" (FREIRE, 1997). O título, em suas edições de 1996 e de 2011, é citado cinco vezes, sendo quatro delas no PPC do IFCatarinense (2013) e uma vez no da UFRPE (2004). Não é citado, entretanto, no PPC de Licenciatura em Ciências Agrícolas do IFRS (2013). Todas as quatro citações do referido título no PPC de Licenciatura em Ciências Agrícolas do IFCatarinense estão demarcadas no contexto das ementas de quatro componentes curriculares, quais sejam: Introdução às Ciências Agrícolas (p. 26), Didática I (p. 42), Estágio Supervisionado III (p. 59) e Estágio Supervisionado VI (p. 64).

No caso do PPC analisado no âmbito da Universidade Federal Rural de Pernambuco (UFRPE, 2004), na realidade, o título "Pedagogia da autonomia: saberes necessários à prática educativa" (FREIRE, 1997) não consta entre as referências do documento, entretanto, já na parte introdutória é trazida a perspectiva do inacabamento do ser, tratando da sua inconclusão para destacar que aquele PPC se trata de um projeto em construção. Tal fragmento se encontra em Freire (1997), daí o consideramos como mais uma citação de Freire que, embora não presente nas referências do documento, está seguramente implícita no texto analisado, senão vejamos: "Paulo Freire [...] defende que 'na verdade o inacabamento do ser ou a sua inconclusão é próprio da experiência vital'. Sendo este projeto trabalhado por pessoas, este é, em essência, radical e ontologicamente, um projeto em construção" (UFRPE, 2004, p.1).

O PPC de Licenciatura em Ciências Agrícolas da UFRPE tem outras duas referências de Freire, não presentes em nenhum dos outros documentos analisados neste estudo e que estão citadas na ementa do componente curricular "Fundamentos da Educação", quais sejam: “Ação Cultural para a liberdade" (FREIRE, 1978 apud UFRPE, 2004, p. 23), e "Concepção Dialética da Educação" (FREIRE, 1971 apud UFRPE, 2004, p. 23).

Semelhantemente, o PPC analisado referente ao curso oferecido pelo Instituto Federal de Educação, Ciência e Tecnologia do Rio Grande do Sul - IFRS, traz também uma referência de Freire que lhe é exclusiva, considerando o conjunto de documentos analisados no presente estudo: "A importância do ato de ler, em três artigos que se completam" (FREIRE, 1994 apud IFRS, 2013, p. 87), desta feita no âmbito da ementa do componente curricular "Educação de Jovens e Adultos). 


\section{Conclusões}

Pelo presente estudo é possível inferir que ainda é muito pequeno o uso do referencial de Freire na construção dos projetos pedagógicos dos Cursos de Licenciatura em Ciências Agrícolas no ambiente das instituições federais de ensino no país, o que não quer dizer que o aporte freireano não esteja inserido no contexto da oferta das disciplinas do curso, notadamente naquelas vinculadas às ciências humanas. Aqui cabe destacar que o PPC pode não traduzir de forma completa a realidade daquilo que se aborda na sala de aula.

O enfrentamento das questões de natureza sócio-política-ambiental contemporâneas, onde as instituições de educação exercem importante papel na formação de cidadãos críticoreflexivos, assume, no caso mais específico da formação profissional direcionada aos trabalhos que envolvem as problemáticas do meio rural, o desafio de (re)pensar seus projetos de educação, trazendo para eles a perspectiva transformadora, sintonizada às necessidades da maioria da população. Neste sentido, as contribuições de Freire, muito para além da obra “Extensão ou Comunicação?” e "Pedagogia da autonomia: saberes necessários à prática educativa" precisam estar mais presentes, norteando de maneira bastante efetiva os processos de construção participativa dos novos rumos para a formação dos licenciados em Ciências Agrícolas no país.

\section{Referências}

CALLOU, Angelo Brás Fernandes et. al. O estado da arte do ensino da extensão rural no Brasil. In: Revista Extensão Rural, ano XV, n. 16, p. 84-115, Jul. - Dez, 2008.

FEITOSA, André Elias Fidelis. A trajetória do Ensino Agrícola no Brasil no contexto do capitalismo dependente. Rio de Janeiro, 2006. 178 p. Dissertação (Programa de Pósgraduação em Educação). Universidade Federal Fluminense, 2006.

FREIRE, Paulo. A importância do ato de ler, em três artigos que se completam. 14. ed. São Paulo: Editora Cortez, 1994.

Ação Cultural para a liberdade. Rio de Janeiro: Editora Paz e Terra, 1978.

. Concepção Dialética da Educação. Rio de Janeiro: Paz e Terra, 1971.

Extensão ou comunicação?. Rio de Janeiro: Editora Paz e Terra, 2014.

. Pedagogia da autonomia: saberes necessários à prática educativa. São Paulo: Editora Paz e Terra, 1997. 
INSTITUTO FEDERAL DE EDUCAÇÃO, CIÊNCIA E TECNOLOGIA CATARINENSE IFCatarinense. Projeto Pedagógico de Curso superior (PPCS): Licenciatura em Ciências Agrícolas. Araquari - SC, 2013. 89 p.

INSTITUTO FEDERAL DE EDUCAÇÃO, CIÊNCIA E TECNOLOGIA DO RIO GRANDE DO SUL. Projeto Pedagógico do Curso de Licenciatura em Ciências Agrícolas. Sertão RS, 2013. 142 p.

MARIANI, Fábio; CARVALHO, Ademar de Lima. A formação de professores na perspectiva da educação emancipadora de Paulo Freire. In: IX Congresso Nacional de Educação, 2009, Curitiba - PR. Anais do IX Congresso Nacional de Educação, 2009.

MORAES, Marco Antonio de. A formação de licenciados em Ciências Agrícolas/Agrárias: o conhecimento e suas conexões. Educação. Santa Maria - RS, v. 39, n. 3, p. 641-652, Set./Dez. 2014.

MOREIRA, Cirdes Nunes; ARAÚJO, Monica Lopes Folena. Educação Ambiental nos Cursos de Agronomia das Universidades Federais Rurais do Norte e Nordeste do Brasil. VI Encontro de Pesquisa Educacional em Pernambuco - EPEPE. Petrolina - PE. Anais do VI Encontro de Pesquisa Educacional em Pernambuco, 2016.

OLIVEIRA, Maria Marly de. Como fazer pesquisa qualitativa. Petrópolis, RJ: Vozes, 2007.

SANTOS, Oséias do; BENEVIDES, Aline de Arruda. A Licenciatura em Ciências Agrícola do IFMT - Campus CONFRESA: formação e extinção. In: XII Congresso Nacional de Educação, 2015, Curitiba - PR. Anais do XII Congresso Nacional de Educação, 2015.

SOUZA, Sandra Elisa Réquia. A inserção da Educação Ambiental no Currículo do Curso de Agronomia: um estudo de caso na UFSM. Dissertação de Mestrado do Programa de Pósgraduação em Educação. Universidade Federal de Santa Maria. Santa Maria - RS: 2006.

UNIVERSIDADE FEDERAL RURAL DE PERNAMBUCO - UFRPE. Proposta de Reformulação do Curso de Licenciatura em Ciências Agrícolas. Recife - PE, 2004. 31 p.

UNIVERSIDADE FEDERAL RURAL DO RIO DE JANEIRO - UFRRJ. Licenciatura em Educação do Campo: Projeto Pedagógico do Curso. Seropédica - RJ, 2010. 87 p.

VEIGA, Ilma Passos Alencastro. Docência Universitária na Educação Superior. In: RISTOFF, Dilvo e SEVEGNANI, Palmira (Orgs.). Docência na educação superior. Brasília: Instituto Nacional de Estudos e Pesquisas Educacionais Anísio Teixeira, 2006, p. 8596.

VIDAL, Diana Gonçalves. A docência como uma experiência coletiva: questões para debate. In: DALBEN, Ângela; DINIZ, Júlio; LEAL, Leiva e SANTOS, Lucíola. (Orgs.). Convergências e tensões no campo da formação e do trabalho docente: didática, formação de professores e trabalho docente. Belo Horizonte: Autêntica, 2010, p. 711-731. 